ПОИСКИ ФОРМЫ И ОБРАЗА ХРАМА В

ПОЗДНЕЙ РОССИЙСКОЙ ИМПЕРИИ (МАРГИНАЛИИ НА СТРАНИЦАХ «БОЛЬШОЙ» ИСТОРИИ АРХИТЕКТУРЫ)

\author{
Илья Евгеньевич Печёнкин \\ кандидат искусствоведения \\ доцент, заведующий кафедрой истории русского искусства \\ факультета истории искусства РГГУ \\ 125993, Москва, Миусская площадь, д. 6 \\ pech_archistory@mail.ru
}

Для цитирования: Печёнкин И. Е. Поиски формы и образа храма в поздней Российской империи (маргиналии на страницах «большой» истории архитектуры) // Вестник церковного искусства и археологии. 2020.3 (4). С. 000. DOI:

\begin{abstract}
Аннотация
УДК

В статье предпринята попытка дать описание истории поисков образа православного храма как современного здания в поздней Российской империи (сер. XIX - нач. XX в.). В литературе церковное зодчество этого периода освещается, главным образом, через рамку стиля. Действительно, вопросы стилеобразования были очень важны для современников: и критики, и сами архитекторы много писали о необходимости строить храмы в традиционных национальных формах и т.д. Однако к этому дискурс о церковной архитектуре в индустриальную эпоху не сводился. В условиях роста населения городов и численности прихожан, внедрения новых материалов и конструкций в строительстве, наконец, в новых культурно-мировоззренческих реалиях, вопрос о храмовой архитектуре получал новые аспекты. Представляет интерес то, каким рисовало себе современную храмовую архитектуру культурное воображение современников.
\end{abstract}

Ключевые слова: русская архитектура, история архитектуры, храмоздательство, культурное воображение, Российская империя, XIX в.

Отечественная культура имперского периода неизменно характеризовалась особым внутренним напряжением, вызванным коллизией отношений между светским и религиозным. Московское царство, Россия была провозглашена Российской империей в год отмены Патриаршества, став одним из результатов петровской секуляризации. На протяжении всего XVIII в. культура высших слоёв общества (в первую очередь, двора и придворной элиты) развивалась исключительно как светская, усваивая практики и формы, принятые в обиходе западной аристократии. Параллельно с этим, существовало пространство низовой культуры, не являвшейся объектом целенаправленной модернизации и европеизации, а потому успешно 
сохранявшей верность традициям позднего Средневековья. Опыт раскрытия религиозной темы присутствовал в этих двух мало пересекавшихся контекстах, и этот опыт был столь же различен, как не похожи друг на друга, например, вологодская церковь Покрова на Торгу (1778-1780) и расположенный в черте нынешнего города Пушкина Софийский собор, заложенный Екатериной II (Ч. Камерон, И. Е. Старов, 1782-1788).

В данной статье я попытаюсь обозначить не вполне традиционный подход к описанию развития храмостроения в России Нового времени ${ }^{1}$, во главу угла которого положен не принцип стилистической классификации (его продуктивность несомненна, однако ограниченна ввиду условности понимания стиля в рассматриваемую эпоху), а метод, позволяющий рассматривать морфологию архитектуры этого времени как открытую систему. Лексикон формальных элементов, связанных между собою не столько семантическими значениями, сколько силой традиции, запечатлённой в конкретных образцах исторических стилей, был слишком узок для трансляции смыслов, которые ассоциировались у современников с религиозной архитектурой. Трансформация смыслов влекла за собой поиски новых форм, и ярче всего эти искания проявились на периферии архитектурного процесса, в стороне от «столбовой дороги» академизма, который с равным успехом эксплуатировал сначала формальный арсенал классицизма, а затем - эклектики.

K началу XIX в. в архитектуре Российской империи безраздельно господствовал классицизм, являвшийся не только стилем зодчества, но также действенным инструментом преобразования пространства, придания ландшафту регулярности и визуального единства. Осуществлялась эта работа с помощью образцовых проектов, благодаря которым классицистические приёмы внедрялись и в провинциальное строительство. В 1824 г.

1 Опыт систематического описания истории церковной архитектуры в России XIX - н. XX в. именно в стилевом аспекте был предпринят о. Александром (Берташем).

(Берташ A. В. Содержание и эволюция русского стиля в церковной архитектуре с. XIX н. ХХ в. // Искусство христианского мира. Вып. 2. М., 1998. С. 113-126). 
Министерством внутренних дел был выпущен первый альбом проектов церквей, подготовленный архитекторами И. И. Шарлеманем и А. А. Михайловым ${ }^{2}$. Включённые в него проектные решения — купольные здания с портиками, ротонды, вытянутые зальные постройки с простыми стропильными перекрытиями - учитывали, кажется, всё многообразие внешних условий и возможностей храмоздателей. Единственное, что объединяло их - это обработка фасадов, выдержанная в стиле ампир (ил. 1 a, б).

Регулярность классицизма, обеспечивавшая возможность его тотального использования в архитектуре казённых зданий, оборачивалась важным недостатком: по мере нарастания объёмов строительства здания получали всё более обезличенный, стандартный характер, утрачивая художественную оригинальность приёмов. Кроме того, не удовлетворял классицизм и тем требованиям к архитектурной образности, которые соответствовали новой внутриполитической доктрине, выраженной в знаменитой триаде графа С. С. Уварова: «Православие, самодержавие, народность». Религиозно-конфессиональная самоидентификация стоит в этой формуле на первом месте, так что поворот архитектуры от классицизма к образам «древнерусским» и «византийским» случился именно в сфере церковного строительства. Поворот этот связан с именем К. А. Тона, которого по праву считают основоположником «русско-византийского стиля». В ноябре 1830 г. император Николай I лично одобрил составленный Тоном проект Екатерининской церкви на Петергофском проспекте, чему предшествовала тянувшаяся несколько лет история, в ходе которой императором были отвергнуты проекты таких именитых архитекторов-классицистов, как А. И. Мельников и А. А. Михайлов ${ }^{3}$ (один из авторов альбома 1824 г.).

2 Собрание планов, фасадов и профилей для строения каменных церквей с кратким наставлением как о самом производстве строения, так и о вычислении потребных к тому материалов; при чем приложены и объяснительные чертежи важнейших частей зданий, с обозначением размера оных для практического употребления. СПб., 1824.

3 Пунин А. Л. Архитектура Петербурга с. и второй пол. XIX в. Т. 1: 1830-60-е г. Ранняя эклектика. СПб., 2009. С. 83. 
Благосклонность монарха обеспечила Тону блестящую карьеру и шумный успех его последующих произведений, включая проект Храма Христа Спасителя в Москве (1831). Альбомы проектов Тона в «русско-византийском стиле» были затем изданы и предписаны в качестве образцовых для строительства православных церквей ${ }^{4}$ (ил. 2 a, б, в).

История утверждения Тоновской версии церковной архитектуры обстоятельно освещена в литературе ${ }^{5}$. Но этот «официальный» ракурс воззрения на религиозную тему в архитектуре, не был единственным в середине XIX в., поскольку речь идёт об эпохе романтизма, сфокусированной на религиозных (в первую очередь, христианских) идеях и образах, как бы «переоткрытых» новоевропейской культурой. Художественный опыт романтиков часто имел внеконфессиональную природу, либо формировался на стыке конфессиональных формаций, отражая характерную для романтического мироощущения волю к перемене мест и состояний. Примерами такого «бегства» может служить история братства «назарейцев» или деятельность О. Н. У. Пьюджина, стремившихся от протестантизма к католицизму, который ассоциировался ими с определёнными художественными феноменами и традициями (ренессансной живописью и готической архитектурой соответственно).

Следует иметь в виду также то, что образ архитектуры XIX столетия не исчерпывается пресловутым «маскарадом стилей», да и сама эта склонность к поверхностным перевоплощениям была одним из проявлений более общей и более фундаментальной установки. В хрестоматийной статье Н. В. Гоголя 1835 г. эта установка хорошо артикулирована: все многочисленные стили, вся

4 См.: Церкви, сочинённые архитектором Е. И. В. профессором архитектуры Императорской Академии художеств и членом разных иностранных академий Константином Тоном. СПб., 1838.; Практические чертежи по устройству церкви Введения во храм Пресвятыя Богородицы в Семеновском полку в С.-Петербурге, составленные и исполненные архитектором Е. И. В. профессором архитектуры Императорской Академии художеств и членом разных иностранных академий Константином Тоном. М., 1845.

5 См.: Кириченко Е. И. Русская архитектура 1830-1910-х г. М., 1978.; Лисовский В. Г. «Национальный стиль» в архитектуре России. М., 2000; Павлова А. Л. Русский стиль в церковной архитектуре XIX в. Храмы соборного типа. М., 2002. 
эта историко-художественная эрудиция является в глазах романтика средством для созидания новой культуры, ступенью возвышения которой была всякая отжившая цивилизация ${ }^{6}$. В этом контексте переклички с прошлым значимы не сами по себе, а как свидетельство интеллектуальных возможностей текущего века, который не в меньшей степени характеризовался верой в прогресс и упованиями на будущее. Оптимистичная футурология позапрошлого столетия воплощалась в формате всемирных выставок, в которых В. В. Стасов видел залог мирного и уважительного сосуществования народов «после варварских и нелепых наполеоновских войн» ${ }^{7}$. Не могли подобные настроения не отразиться и на религиозных воззрениях современников.

Интересен пример А. А. Иванова, создавшего самую значительную в русском искусстве Нового времени картину на евангельский сюжет и оказавшего кардинальное влияние на художников второй половины XIX в. В начале 1850-х гг. ему пришлось переосмыслить библейские темы сквозь призму современной истории, с её бурными общественно-политическими процессами. Он начинает мечтать о грандиозном произведении, превосходящем своими масштабами всё, что доводилось создавать русским художникам. Отечественная академическая школа, представителем которой являлся Иванов, возникла во второй половине XVIII в. в результате импорта французской модели художественного образования и регулирования художественного процесса, в течение всего имперского периода обнаруживал неразрывную связь с интернациональным контекстом. Не удивительно то, что в рамках занятий исторического класса Академии композиции на религиозные сюжеты решались в духе западноевропейских образцов. Но и содержательная сторона этой религиозности была обусловлена в наибольшей степени не конкретной конфессиональной традицией, а европейской образованностью.

6 Гоголь Н. В. Об архитектуре нынешнего времени // Полное собрание сочинений. Т. 8: Статьи. М.; Л., 1952. С. 56-75.

7 Стасов В. В. Искусство ХІХ в. Архитектура // Избранные сочинения. Т. 3. М., 1952. C. 500. 
В письме к В. В. Стасову от 15 мая 1862 г. брат художника, архитектор С. А. Иванов, вспоминал о намерении автора «Явления Мессии» «сделать в композициях жизнь и деяния Христа $<\ldots>$ в особо на это посвящённом здании, разумеется, не в иееркви (курсив мой - И. П.)» ${ }^{8}$. Этот момент примечателен: по всей вероятности, история человеческая занимала Иванова более, чем священная история. Задуманная им роспись должна была состоять из 22 циклов, каждый из которых имел в центре своём композицию на евангельский сюжет, окружённую исполненными в меньшем масштабе близкими по содержанию сценами из Ветхого Завета и даже из античной мифологии. Чисто романтическая (и вполне утопичная) идея созидания некоего исчерпывающего художественного труда, приняла у Иванова фантастический облик светского «храма», трактованного как «результат всех верований, отданных на разбор последней нации на планете земля» ${ }^{9}$.

При всём своеобразии проекта Иванова, его представляется возможным вписать в панораму религиозно-художественных исканий своего времени. Изучению феномена «любительского» проектирования религиозных зданий (которые на самом деле мыслились их авторам объектами не столько сакральными, сколько идеологическими) уделила внимание в одном из своих трудов Е. И. Кириченко. В качестве раннего примера (1822) она приводит курьёзное предложение некоего титулярного советника П. П. Шеншина, служившего квартальным надзирателем. Суть его сводилась к созданию особого рода заведения, являвшегося одновременно домом молитвы и морального воспитания. Вероятно, дидактический аспект этого замысла был обусловлен опытом полицейской службы его автора, видевшего цель свою в том, чтобы «отвести или, по крайней мере, отвадить всякого человека от

8 ОР РПБ. Ф. 738. Ед. хр. 303 (1862). Л. 8. Цит. по: Степанова С. С. Хроника жизни и творчества Александра Андреевича Иванова // Александр Андреевич Иванов, 1806-1858. M., 2006. C. 241.

9 Плотникова Е.Л. Восхождение. От академических картонов до Библейских эскизов // Там же. С. 132-133. 
грехопадения <..> и приводить народ к истинному евангельскому просвещению» ${ }^{10}$.

Однако в середине и второй половине столетия тема нравственного просвещения неотрывна от исторического знания. Сама концепция храма и, одновременно, памятника недвусмысленно говорит о важности той роли, которая отводилась в политической программе позднего российского самодержавия образам «полезного прошлого». Транслированные через произведения художников и архитекторов официальной Академии, эти образы находили благодатную почву в душах некоторых амбициозных подданных, которые пытались конструировать собственные варианты сверхсооружений — беспрецедентных по идейной широте и необычайных по своим формам. Важно подчеркнуть, что решительно во всех известных нам «любительских» проектах храмов-памятников прослеживается общая тенденция поставить архитектуру в прямую зависимость от библейского текста, рассматривать архитектурную морфологию как своего рода иероглифическое письмо. Это существенно отличалось от того направления, в котором двигались профессиональные зодчие, ставившие во главу угла задачу отыскания некоего целостного стиля, который соответствовал бы самоидентификации российской элиты и, как следствие, империи в целом.

«Возрождение» для такой задачи определённого и единого в своей формальной лексике стиля осталось утопией. Известно, что Константин Тон, по его собственным словам, культивировавший стиль «Византийский, сроднившийся с древних времён с элементами нашей народности» ${ }^{11}$, на деле в своих проектах монтировал вместе элементы классицизма и допетровских построек Московского Кремля. Подобным же образом А. М. Горностаев, которого его биограф В. В. Стасов вывел в качестве Тоновского антипода, был

10 Кириченко Е. И. Запечатленная история России. Монументы XVIII - начала XX в. Кн. 1. М., 2001. С. 302.

11 Церкви, сочинённые архитектором Е. И. В. профессором архитектуры Императорской Академии художеств и членом разных иностранных академий Константином Тоном. С. 1. 
вынужден сочетать в своих церковных постройках мотивы русских средневековых памятников с формами романской архитектуры, прежде всего итальянской. Объясняя такую тактику своим читателям, Стасов писал следующее: «Не находя достаточно материалов в памятниках русских, он стал искать их в произведениях искусства того же времени других стран. Вот почему в некоторых его постройках, исполненных в русском стиле, встречаются элементы романской архитектуры» ${ }^{12}$.

Непрофессиональные архитекторы, не скованные необходимостью компоновать свои проекты в тех или иных исторических стилях, оказывались в более выгодном положении. Эта свобода, помноженная на изобретательность, часто присущую мыслителям «из народа», порождала такие произведения, как проект «Храма Триединому Богу» некоего М. Лебедева, представлявший собой несколько эскизных чертежей в сопровождении пространного пояснительного текста и опубликованный в популярной иллюстрированной газете «Пчела», редакторами которой являлись А. В. Прахов и М. О. Микешин - лица, весьма известные на поприще искусства. Существенно, что перед нами именно храм-памятник, призванный увековечить момент «поворота России на 2-ое тысячелетие, начиная с освобождения крестьян и других преобразований настоящего царствования (императора Александра II. - И. П.)» ${ }^{13}$.

Прежде всего следует раскрыть личность автора проекта. Е. И. Кириченко, включившая проект Лебедева в свой обзор любительских опытов храмотворчества, оставила этот вопрос без внимания. Однако в современных исследованиях по истории богословской мысли XIX в. упоминается профессор Киевской духовной академии М. Лебедев, публиковавший статьи с критикой спиритизма, который вошёл в моду во второй половине столетия ${ }^{14}$. В. С.

12 Стасов В. В. А. М. Горностаев // Вестник изящных искусств. 1888. Т. 6. Вып. 6. C. 461.

13 Храм Божий, или Дом Молитвы, по проекту г. Лебедева // Пчела: русская иллюстрация. 1877. № 6. С. 95.

14 Речь идёт, в частности, о статье: Лебедев M. Спириты и спиритизм // Христианское чтение. 1866. № 7. С. 24-101; № 9. С. 265-315; № 11. С. 615-707. 
Раздьяконов характеризует Лебедева как автора, писавшего в рамках историко-филологической традиции и определявшего спиритизм как новейшую христианскую ересь ${ }^{15}$. В пользу того, что автор проекта «Храма Триединому Богу» и критик спиритизма в духовных журналах — одно и то же лицо, говорит богословская осведомлённость Лебедева из «Пчелы». При этом мысль его, правда, отличает известная лёгкость, позволяющая весьма нетривиальные ходы. От вопросов богословских он устремляется к апологии научного прогресса, фантазирует о необходимости заменить в куполе традиционную живопись иллюминацией из «звёзд электрических» ${ }^{16}$. Сакральное пространство у него отождествляется с декорациями, изображающими физический космос ${ }^{17}$ (ил. 3 a, б).

«Храм Триединому Богу скомпонован внутри на тему “небеса небес”, пишет Лебедев, - и потому в плане имеет небесные линии - круги и эллипсы, а наружная компоновка сделана на тему крепости. Мотив крепости основан на следующих соображениях. Если египтянин берёт для своей колонны мотив лотоса или пучок его стволов <...>; если древний грек берёт завиток бересты мотивом для ионической колонны <...>; если римский купол имеет мотивом небо, а готическая архитектура — лес, то можно брать и другие мотивы для художественных зданий, в частности, и крепость, особенно если последняя окажется совпадающею с религиозными идеями. <..> В религиозном же отношении мотив крепости совершенно приличен христианскому храму. Стоит только напомнить изречение Спасителя о церкви: “и врата адова не одолеют ю”, а также богословское наименование церкви на земле “Воинствующею”, в отличие от церкви “Торжествующей”, т.е. небесною < ..> Известно, что города на востоке строились как крепости, а

15 Раздьяконов В. С. Христианский спиритизм Н. П. Вагнера и рациональная религия А. Н. Аксакова между «наукой» и «религией»// Вестник ПСТГУ. Серия I: Богословие. Философия. 2013. № 4 (48). С. 59.

16 Храм Божий, или Дом Молитвы, по проекту г. Лебедева // Пчела: русская иллюстрация. 1877. № 7. С. 110.

17 На это обратила внимание Е. И. Кириченко, написавшая о близости идей М. Лебедева к философским воззрениям «космиста» Н. Ф. Фёдорова (Кириченко Е. И. Запечатленная история России. Монументы XVIII - начала XX в. Кн. 1. С. 307). 
Сион был цитаделью в Иерусалиме, т. е. крепостью в крепости. Подобное же описание грядущего Иерусалима есть в Апокалипсисе. Затем следует помнить учение апостола Павла, что у нас постоянная борьба с врагом спасения; призывы его облекаться в оружие правды; а также слова Христовы: “Я не мир принёс на землю, но меч". После этого ясно, что брать мотив крепости для христианского храма, значит брать готовый уже и данный самим христианством элемент для художественного воспроизведения» ${ }^{18}$.

Развёрнутая Лебедевым совокупность смыслов требовала привлечения незаурядных выразительных средств. Здесь он, между прочим, постулирует мысль о том, что «архитектура как искусство, как вид языка, выражающего идею, не должна держаться всегда неподвижных форм» ${ }^{19}$. Лебедева не удовлетворяет узкая трактовка стиля как закрытой и неизменной общности формальных приёмов. Описывая свой проект как выдержанный в «византийском стиле» (к слову, законодательно установленном в качестве предпочтительного для церковных зданий ${ }^{20}$ ), Лебедев вводит понятие «стилевания», под которым понимает «постоянное возведение в стиль какихлибо архитектурных мотивов, подходящих к данной идее» ${ }^{21}$.

Примечательно то, что автор проекта допускает и прямые стилевые заимствования, если они отвечают смыслу идейной программы: «Вся алтарная часть составлена на тему “Горнего Иерусалима”, где главный престол на горе и без сени поставлен перед самой бездной, как «подножие ног Его», а шесть боковых алтарей у подошвы гор, выступая к середине храма, составлены во вкусе всех главнейших архитектурных стилей мира <..> 1-й Алтарь, Приснодевы, на тему римской архитектуры <..> 2-й Алтарь, Апостолов $u$ Учителей Церкви — готического стиля < .. > 3-й Алтарь, Мучеников - руссковизантийского стиля < .. > 4-й Алтарь, Бесплотных, на тему греческих храмов

18 Храм Божий, или Дом Молитвы, по проекту г. Лебедева // Пчела: русская иллюстрация. 1877. № 6. С. 95.

19 Там же.

20 Устав строительный. 3-е изд. СПб., 1881. С. 68.

21 Храм Божий, или Дом Молитвы, по проекту г. Лебедева // Пчела: русская иллюстрация. 1877. № 6. С. 95. 
(но трёхъярусный $)<\ldots>5$-й Алтарь, Пророков и Праотиев ветхозаветных мавританского стиля <..> 6-й Алтарь, Преподобных - египетского стиля $<\ldots>$ по панелям стен алтаря живопись всех древностей Египта, населённых христианскими отшельниками, которые заняты своими работами среди развалин языческого мира» 22 (ил. 3 в, г).

Идея такого «парада стилей» в 1870-х гг. была не нова. Практика единовременного экспонирования архитектурных и художественных вкусов разных народов и эпох была характерна для всемирных выставок. В частности, в 1867 г. в Париже можно было видеть расположенные бок о бок «Египетский квартал» и японский павильон, выполненный в национальных традициях, ацтекских идолов и «русские избы» (ил. 4). Однако интересна попытка перенесения этого опыта в религиозную архитектуру; вернее - религиозная мотивация использования такого приёма.

Нельзя не увидеть определённой близости программы Лебедева замыслу А. А. Иванова, хотя последний, как мы знаем, не предполагал видеть задуманное им здание храмом. В обоих случаях, однако, чувствуется воля авторов к переосмыслению функции религиозного искусства. У Иванова вполне откровенно, а у Лебедева менее явно, — но молитвенность вытеснена интеллектуальной рефлексией на историософские темы.

Обе программы, очевидно, отразили вообще присущий эпохе литературоцентризм. Однако, с точки зрения архитектуры (пусть и умозрительной, не отягощённой заботами о физической устойчивости), замысел Лебедева, конечно, выглядит интереснее. Целью его усилий является синтез архитектурной формы и религиозного содержания, невиданный в проектах и постройках зодчих-профессионалов. «Во всех храмах купольной конструкции, — пишет он, - находят раздвоение интересов архитектурного с религиозным; находят, что высший архитектурный интерес <..> сосредоточивается в куполе $<\ldots>$, а $<\ldots>$ высшая религиозная драгоценность сосредоточена в восточной или алтарной части храмов. Здесь же, в 
расположении внутренности Дома Божия, где и верхний центральный купол, и наклонный параболический сливаются один с другим без перерывов, оба имеют одинаковую окраску и одинаковый сюжет <..> возможно полное единство и полное устранение вопроса о раздвоении интересов, сливающихся в один общий интерес изображения беспредельного Царства Божия» ${ }^{23}$.

Подводя итог, стоит подчеркнуть в качестве главной мысль о том, что религиозная проблематика в русской архитектуре XIX в. не может быть исчерпана обсуждением эволюции того или иного неостиля применительно к церковному зодчеству. Не исключено, что вопрос о конкретных мотивах декора имеет третьестепенное значение в сравнении с вопросами типологии и семантики в эпоху, когда храм превращается в одну из разновидностей общественного пространства, а традиционная символическая программа сакрального здания обогащается новыми политическими и натурфилософскими смыслами.

\section{Источники}

Гоголь Н. В. Об архитектуре нынешнего времени // Полное собрание сочинений в 14 т. Т. 8: Статьи / ред. Н. Ф. Бельчиков, Б. В. Томашевский. М.; Л.: АН СССР, 1952. С. 56-75. Лебедев М. Спириты и спиритизм // Христианское чтение: ежемесячное издание при СПбДА. 1866. № 7. С. 24-101; № 9. С. 265-315; № 11. С. 615-707.

Практические чертежи по устройству церкви Введения во храм Пресвятой Богородицы в Семеновском полку в Санкт-Петербурге, составленные и исполненные архитектором Е. И. В. профессором архитектуры Императорской Академии художеств и членом разных иностранных академий Константином Тоном. М.: Тип. А. Семена, 1845.

Собрание планов, фасадов и профилей для строения каменных церквей с кратким наставлением как о самом производстве строения, так и о вычислении потребных к тому материалов; при чем приложены и объяснительные чертежи важнейших частей зданий, с обозначением размера оных для практического употребления. СПб.: тип. Медицинского департамента МВД, 1824.

Устав строительный. СПб.: Тип. придворного книгопр. К. К. Ретгера, 1881.

Храм Божий, или Дом Молитвы, по проекту г. Лебедева // Пчела: русская иллюстрация: еженедельный журнал искусств, литературы, политики и общественной жизни. 1877. № 6. С. 88-121; № 7. С. 110-111.

Церкви, сочинённые архитектором Е. И. В. профессором архитектуры Императорской Академии художеств и членом разных иностранных академий Константином Тоном. СПб.: [б. и.], 1838.

\section{Литература}

23 Там же. С. 123. 
Берташ A. В. Содержание и эволюция русского стиля в церковной архитектуре середины XIX - начала XX в. // Искусство христианского мира. Вып. 2 / отв. ред. А. А. Воронова. М.: ПСТБИ. Факультет церковных художеств, 1998. С. 113-126.

Кириченко Е. И. Запечатленная история России. Монументы XVIII - начала XX века в 2 кн. Кн. 1. М.: Жираф, 2001.

Кириченко Е. И. Русская архитектура 1830-1910-х гг. М.: Искусство, 1978.

Лисовский В. Г. «Национальный стиль» в архитектуре России. М.: Совпадение, 2000.

Павлова А. Л. Русский стиль в церковной архитектуре XIX века. Храмы соборного типа: диссертация кандидата искусствоведения. М.: [б. и.], 2002.

Плотникова E. Л. Восхождение. От академических картонов до Библейских эскизов // Александр Андреевич Иванов, 1806-1858: к 150-летию Государственной Третьяковской галереи; к 200-летию со дня рождения художника / отв. ред. Л. И. Иовлева. М.: Сканрус, 2006. С. 120-135.

Пунин А. Л. Архитектура Петербурга середины и второй половины XIX века. Т. 1: 1830-60е гг. Ранняя эклектика. СПб.: Крига, 2009.

Раздьяконов В. С. Христианский спиритизм Н. П. Вагнера и рациональная религия А. Н. Аксакова между «наукой» и «религией» // Вестник ПСТГУ. Серия I: Богословие. Философия. 2013. № 4 (48). С. 55-72.

Стасов В. В. А. М. Горностаев // Вестник изящных искусств. 1888. Т. 6. Вып. 6. С. 439-480. Стасов В. В. Искусство XIX века. Архитектура // Избранные сочинения в 3 т. Т. 3. М.: Искусство, 1952. С. 485-506.

Степанова C. C. Хроника жизни и творчества Александра Андреевича Иванова // Александр Андреевич Иванов, 1806-1858: к 150-летию Государственной Третьяковской галереи; к 200-летию со дня рождения художника / отв. ред. Л. И. Иовлева. М.: Сканрус, 2006. С. 225-247.

\title{
The Searching for the Image of Church Building through the Late Russian Empire (Marginalia of a Mainstream Architectural History)
}

\author{
Ilia E. Pechenkin \\ $\mathrm{PhD}$, Associate Professor \\ Head of Department of a History of Russian Art \\ at the Faculty of Art-History, Russian State University for the Humanities \\ 6 building, Miusskaya Square, 125993. Moscow, Russia \\ pech archistory@mail.ru
}

For citation: Pechenkin, Ilia E. "The Searching for the Image of Church Building through the Late Russian Empire (Marginalia of a Mainstream Architectural History)". Church Art and Archeology Review, № 3 (4), 2020, pp. 000 (in Russian). DOI:

Abstract. The article attempts to describe the history a search for an image of the Orthodox church building as a modern structure in the late Russian Empire (mid XIX - early XX centuries). In literature, this period is usually given through the style framework. Indeed, a question of style formation had been highly important for contemporaries as both critics and architects wrote a lot about producing churches in traditional national forms, etc. However, it would not be enough for a church architecture of the industrial era experiencing the growth of city population that expressed in a bigger number of parishioners, the usage of new materials and building structures and, finally, the new cultural and worldview realities. It is interesting how the cultural imagination of its contemporaries depicted a modern temple architecture of that time.

Keywords: Russian architecture, architectural history, church building, cultural imagination, Russian Empire, XIX century. 


\section{References}

Bertash A. V. (1998) "Soderzhanie i evolyuciya russkogo stilya v cerkovnoj arhitekture serediny XIX - nachala XX vekov" ["The Content and Evolution of the Russian Style in Church Architecture of the Mid XIX - Early XX Centuries"]. Iskusstvo hristianskogo mira, iss. 2, pp. 113-126 (in Russian).

Gogol' N. V. (1952) "Ob arhitekture nyneshnego vremeni" ["On the Architecture of the Present Time"], in Bel'chikov N. F., Tomashevskij B. V. (eds.) Polnoe sobranie sochinenij v $14 t$. [Complete Works in 14 vols.]. Moscow; Leningrad: AN SSSR, vol. 8, pp. 56-75 (in Russian).

Kirichenko E. I. (1978) Russkaya arhitektura 1830-1910-h godov [Russian Architecture of the 1830s-1910s]. Moscow: Iskusstvo (in Russian).

Kirichenko E. I. (2001) Zapechatlennaya istoriya Rossii. Monumenty XVIII - nachala XX veka v 2 knigah [The Imprinted History of Russia. Monuments of the XVIII - Early XX Century in 2 Books]. Moscow: Zhiraf, book 1 (in Russian).

Lisovskij V. G. (2000) "Nacional'nyj stil" v arhitekture Rossii ["National Style" in the Architecture of Russia]. Moscow: Sovpadenie (in Russian).

Pavlova A. L. (2002) Russkij stil'v cerkovnoj arhitekture XIX veka. Hramy sobornogo tipa: dissertaciya kandidata iskusstvovedeniya [Russian Style in Church Architecture of the XIX Century. Temples of the Cathedral Type: Dissertation of the Candidate of Art History]. Moscow: [b. i.] (in Russian).

Plotnikova E. L. (2006) "Voskhozhdenie. Ot akademicheskih kartonov do Biblejskih eskizov" ["Ascent. From academic cartons to Biblical sketches"], in Iovleva L. I. (ed.) Aleksandr Andreevich Ivanov, 1806-1858: $k$ 150-letiyu Gosudarstvennoj Tret'yakovskoj galerei; $k$ 200-letiyu so dnya rozhdeniya hudozhnika [Aleksandr Andreevich Ivanov, 1806-1858: To the 150th Anniversary of the State Tretyakov Gallery; to the 200th Anniversary of the Artist's Birth]. Moscow: Skanrus, pp. 120-135 (in Russian).

Punin A. L. (2009) Arhitektura Peterburga serediny i vtoroj poloviny XIX veka [Architecture of St. Petersburg in the Middle and Second Half of the XIX Century]. Saint-Petersburg: Kriga, vol. 1 (in Russian).

Razd'yakonov V. S. (2013) "Hristianskij spiritizm N. P. Vagnera i racional'naya religiya A. N. Aksakova mezhdu 'naukoj' i 'religiej"” [“N. P. Wagner's Christian Spiritism and A. N. Aksakov's Rational Religion between 'Science' and 'Religion'”]. Vestnik PSTGU. Seriya I: Bogoslovie. Filosofiya, no. 4 (48), pp. 55-72 (in Russian).

Stasov V. V. (1952) "Iskusstvo XIX veka. Arhitektura" ["The Art of the XIX Century. Architecture"], in Izbrannye sochineniya $v 3$ t. [Selected Works in 3 vols.]. Moscow: Iskusstvo, vol. 3, pp. 485-506 (in Russian).

Stepanova S. S. (2006) "Hronika zhizni i tvorchestva Aleksandra Andreevicha Ivanova" ["Chronicle of the Life and Work of Alexander Andreevich Ivanov"], in Iovleva L. I. (ed.) Aleksandr Andreevich Ivanov, 1806-1858: $k$ 150-letiyu Gosudarstvennoj Tret'yakovskoj galerei; $k$ 200-letiyu so dnya rozhdeniya hudozhnika [Aleksandr Andreevich Ivanov, 18061858: To the 150th Anniversary of the State Tretyakov Gallery; to the 200th Anniversary of the Artist's Birth]. Moscow: Skanrus, pp. 225-247 (in Russian). 